\title{
Biografia de Clarice, por Benjamin Moser: coincidências e equívocos
}

Benjamin Abdala Junior

$\mathrm{E}$ M 1995, por ocasião do lançamento de Clarice, uma vida que se conta, um estudo sobre a vida e obra de Clarice Lispector, de autoria da professora Nádia Battella Gotlib, publiquei algumas notas críticas para a revista Teoria e Debate (n.30, nov./dez. 1995). Nessa resenha, procurei destacar a inclinação da autora no sentido de apreender Clarice, persona e obra, no que a escritora apresenta de mais desafiador:

Para Clarice Lispector, a vida implicava criação sem os espartilhos das teorias e sobretudo das certezas que as enformam. É dessa maneira que a biografia literária de Nádia Battella Gotlib vai se atrever a montar o retrato polifacetado da escritora sem apriorismos, através das vozes que contam.

Ressaltei também nesse texto o nível de reflexão crítica da autora, atenta à "inquietação" que provoca a literatura de Clarice, e alerta ao "caráter problemático dos conceitos de imitação e de verdade". E mais:

Logo, não se encontram nele traços inequívocos de um certo gênero de biografias voltado para perfis capazes de constituir paradigmas de ação para situações previsíveis. Um retrato assim produzido seria uma traição à própria Clarice, que sempre manteve um olhar enviesado para os atores sociais de comportamento estereotipado e personagens de caráter ritualizado.

Remeto uma vez mais a esse livro, que se transformou em leitura fundamental para os interessados na biografia e na li- teratura de Clarice Lispector e que vem sendo sistematicamente consultado pelos estudiosos no assunto. O livro, tese de livre-docência defendida na USP em 1993, editado em 1995 pela Ática, nesse mesmo ano teve quatro reimpressões. Mais recentemente, em edição revista, foi traduzido para o espanhol na Argentina (Ed. Adriana Hidalgo, 2007). E ganhou edição revista também em português, já com o selo da Edusp, em 2009, com acréscimo de meia página (leitura de uma foto) e atualização de dados. Aliás, essa atualização deveu-se também a outra pesquisa desenvolvida pela mesma autora, que gerou outro livro seu, intitulado Clarice fotobiografia (Edusp/Imprensa Oficial do Estado de São Paulo, 2008) uma narrativa visual de história de vida e obra de Clarice, com 800 imagens.

Volto ao livro Clarice, uma vida que se conta, agora motivado pela leitura de outra biografia de Clarice Lispector, publicada em 2009, feita por Benjamin Moser, e que recebeu o título Clarice,. E busco as razões pelas quais a leitura dessa recente biografia de Moser me conduziu, a todo momento, à biografia de Clarice publicada por Gotlib quinze anos atrás.

As recorrências ao texto escrito por Nádia Gotlib começaram a partir da leitura de um folheto de apresentação do livro de Moser. Num primeiro momento, estranhei o título. Fica-se esperando por uma complementação que, no entanto, não existe. $\mathrm{Ou}$, num segundo momento, após o estranhamento, o título pode levar à expectativa de "uma vida que se conta", 
nas páginas interiores do livro. Há, entretanto, uma explicação da editora, no folheto que acompanha o exemplar e que tenta esclarecer a opção: o título surge "numa associação com a vírgula que inicia o romance Uma aprendizagem ou o $l i$ vro dos prazeres". Curiosamente, chegoume às mãos, depois, a coletânea poética de Armando Freitas Filho, anteriormente publicada (junho, 2009), que se valeu do mesmo recurso (Lar,. São Paulo: Cia. das Letras).

Ora, a vírgula empregada justamente no início do romance de Clarice tem função muito peculiar. Continua-se uma história que já teve o seu início em algum momento, início de história que, ali, não aparece. Já no título do livro, o próprio fato de se usar a vírgula depois de um nome, um nome bem conhecido (Clarice), faz que toda a possível correlação que possa ter com o seu uso no início do romance, aqui, se desfaça. Assim sendo, melhor seria o leitor tecer suas próprias considerações sobre o título, deixando sua imaginação fluir.

Há ainda no folheto outras considerações. Afirma-se que "numa pesquisa inédita, o autor percorreu todos os lugares por onde os Lispector passaram”. Outros já por lá andaram, como a própria autora da biografia anterior a que nos referimos quando complementava os dados para elaboração da sua fotobiografia. Ainda no folheto menciona-se "outro ponto alto do livro", a escrita de Benjamin Moser, que soube encadear "trechos da obra de Clarice, de seus contemporâneos, depoimentos e documentos inéditos". Mais um procedimento nada original, que está patente em outras biografias de Clarice: tanto na já citada quanto na elaborada por Teresa Cristina Montero Ferreira, publicada com o título Eu sou uma per- gunta. Uma biografia de Clarice Lispector, em 1999 (Rocco).

Finalmente, o folheto realça "a habilidade narrativa de Moser", "também visível nas relações que ele tece entre vida e obra". E continua: "Não se trata de explicar de maneira reducionista a vida pela obra ou vice-versa, mas fazer com que uma funcione como caixa de ressonância de outra". Esse texto me faz remeter a um trecho do livro de 1995 de Nádia Gotlib. Na apresentação, a autora afirma: "Neste livro entrelaçam-se vida e obra de Clarice Lispector. Dados de informação de ordem biográfica e dados de leitura crítica de seus textos alternam-se e complementam-se, sem que, equivocadamente, se estabeleçam mútuas relações de dependência” (p.15).

Seria mera coincidência?

E o folheto prossegue: "a cada capítulo o narrador se volta para o livro que Clarice estava escrevendo ou publicando naquele momento, o que faz da biografia também um guia de leitura, uma porta de entrada para o universo clariciano". É exatamente esse mesmo procedimento o adotado pela antecessora Nádia Gotlib, quinze anos antes...

Após tais alertas, abertos pelo próprio folheto, parti para a leitura do livro. Logo no primeiro capítulo, Moser recorre à passagem de Clarice pelo Egito e as visões da escritora por diferentes personalidades, para concluir que ela permanece como enigma. É essa a proposta do primeiro capítulo do livro de Nádia Gotlib, que aponta para várias visões de Clarice "pela empregada, pela vizinha, pelos parentes, amigos, jornalistas, críticos, escritores" (p.54), para concluir que... Clarice permanece como enigma.

Ao longo dos capítulos, uma estrutura semelhante: capítulos curtos, com títulos 
sugestivos, que percorrem praticamente, na sua grande maioria, os mesmos textos. Aliás, parte desses textos foi também utilizada por Teresa Montero, no seu livro de 1999, em que ela abre novas frentes de leitura de dados biográficos, como, por exemplo, as provenientes da descoberta de processos de naturalização depositados no Arquivo Nacional.

De fato, Moser recorre, salvo dois ou três textos inéditos aí mencionados, a uma mesma massa documental já analisada pelas biógrafas que o antecederam. São, por exemplo, textos críticos que surgem após a publicação dos romances, correspondência trocada entre Clarice e irmãs e entre Clarice e amigos, entrevistas concedidas por Clarice em vários periódicos, sobretudo no Rio de Janeiro.

Os itens desenvolvidos ao longo dos capítulos são também praticamente os mesmos: a turbulência política da Ucrânia assolada por lutas internas e externas e pela perseguição aos judeus, a viagem da família da Ucrânia para o Brasil, a infância de penúria em Maceió e, depois, em Recife, as primeiras leituras, as crônicas de memória, a mudança para o Rio, os primeiros contos e o primeiro romance, a viagem para a Itália durante a Segunda Grande Guerra, sua estada em Berna que a escritora considera "um cemitério de sensações", a amizade com Bluma Wainer, a breve permanência na Inglaterra, a colaboração na imprensa carioca escrevendo páginas e colunas femininas, os vários romances e contos que escreveu ao longo desses anos, a tentativa de reconciliação por parte do marido, os "diálogos possíveis" e demais entrevistas que fez para periódicos no Rio, o período de crônicas publicadas no Jornal do Brasil, os textos escritos nos anos 1970, a presença no congresso de bruxaria na Colômbia, as entrevistas que concede ao Museu da Imagem e do Som do Rio, ao jornal Pasquim, à TV Cultura, e, finalmente, capítulos sobre $A$ hora da estrela e Um sopro de vida, para então finalizar com o capítulo referente à morte da escritora.

$\mathrm{E}$ os fatos referentes à vida de Clarice não oferecem novidade: paixão pelo homossexual Lúcio Cardoso, casamento com Maury Gurgel Valente, união frustrada com Paulo Mendes Campos, amizade com Olga Borelli nos seus últimos anos de vida. Nada de novo, além de, isto sim, e por Moser, informações extensas sobre a dizimação dos judeus na Europa e panoramas referentes a momentos históricos do Brasil, com o sentido de elucidar quem teriam sido algumas das personalidades históricas brasileiras.

As semelhanças não estão só na trilha narrativa. Se no livro de Nádia Gotlib há um subcapítulo intitulado "As receitas da bruxa", no de Moser há capítulo intitulado "A bruxa". No da crítica brasileira há “Os diálogos possíveis", no de Moser há "Diálogos possíveis". Em Clarice, uma vida que se conta há "O furacão Clarice", em Clarice, "Furacão Clarice"...

No final do último capítulo do livro de Benjamin Moser, mais uma coincidência: o autor transcreve a cena de Clarice no hospital quando se dirige à enfermeira para afirmar a dramática frase: "Você matou meu personagem". Moser escolhe, para integrar parte final do último capítulo do seu livro, a mesma cena com que Gotlib termina o seu livro. Há que considerar, é bem verdade, que essa cena, relatada por Olga Borelli a Nádia Gotlib, funciona, no livro de Nádia Gotlib, como clímax de um processo de mergulho na própria ficção, a própria escritora transformando-se em "personagem" de si mesma, derradeira etapa de uma ativi- 
dade narrativa que a crítica acompanha, a pari passu, ao longo das construções ficcionais e jornalísticas de Clarice, com a preocupação de aí detectar os meandros de uma linguagem narrativa desmitificadora e inventiva.

O elemento diferencial da biografia feita por Moser reside, no entanto, no enfoque voltado para as questões judaicas na vida e obra de Clarice. Informações detalhadas sobre a origem dos conflitos no Leste Europeu, responsáveis pelo movimento migratório da população judaica para outros continentes, como para as Américas, servem de respaldo para a história da própria família judia de Clarice, que precisou sair da Ucrânia para o Brasil. Encontram-se ecos dessa cultura em vários momentos do livro, quando o autor se refere a leituras feitas por Clarice (de Espinosa, por exemplo) e a textos escritos por Clarice (em que procura, sobretudo, estabelecer relações com essa cultura de origem).

Justamente, porém, ao tentar privilegiar essa ascendência, o autor recai numa linha de reflexão que desloca seu centro de interesse e, na ânsia de reconstituir um passado de dimensão épica, resvala em riscos de argumentação, que acabam prejudicando o seu fio de exposição.

Dentre esses riscos, cito o que se refere a fatos referentes à mãe de Clarice, já que, a partir daí, tece considerações posteriores. Refere-se a um estupro de que teria sido vítima a mãe da escritora, fato que, no entanto, mostra-se problemático, por suas inconsistências, tal como ali surge, transformado em verdade absoluta, pela via de uma interpretação forçada. Um equívoco, do ponto de vista documental. As razões residem na própria leitura da documentação que o autor usa para comprovar essa sua tese.
Eis, a seguir, os passos da argumentação de Moser.

Logo no início do livro, o autor afirma que a mãe de Clarice foi "condenada à morte por um ato de indizível violência" (p.17). Mas não aparece, em documento nenhum de que o autor se serviu, a explicitação dos detalhes dessa violência, que ele faz, no entanto, questão de ressaltar.

Vale-se, Moser, de uma crônica da Clarice adulta, que se volta num discurso de memória para esse universo da infância (até que ponto imaginário?) para descrever justamente esse fato: a de que foi concebida para salvar a mãe de uma doença. Diz Clarice: "fui preparada para ser dada à luz de um modo tão bonito. Minha mãe já estava doente e, por uma superstição bastante espalhada, acreditava-se que ter um filho curava uma mulher de uma doença" ("Pertencer", em $A$ descoberta do mundo, p.151).

Para Moser, essa doença seria sífilis, causada por estupro que aconteceu durante pogrom realizado por bolcheviques russos. Com certeza absoluta, o autor identifica o crime (estupro), o criminoso (bolcheviques russos) e o diagnóstico de doença "proveniente" desse crime (sífilis).

Moser parte de um trecho de texto inédito de Elisa Lispector, intitulado Retratos antigos. Ela menciona o fato de que "Foi o trauma decorrente de um daqueles fatídicos pogroms que invalidou minha mãe" (p.47-8, a partir de Elisa Lispector, Retratos antigos, p.15). Mas "trauma" não é "estupro". Ou não acontece necessariamente por causa de um estupro.

$\mathrm{O}$ autor de Clarice, faz ainda a seguinte afirmação: "Bem no fim da vida, Clarice confidenciou à amiga mais íntima que sua mãe fora violentada por um bando de soldados russos. Deles, ela contrain sifilis, 
que nas pavorosas condições da guerra civil ficou sem tratamento" (p.48, grifo meu). Clarice, pois, teria dito a uma amiga, que teria dito a outra amiga... Nessa sequência de informações, sem local, nem data, e às vezes sem identificação de depoentes, escapam dados básicos para se considerar o depoimento como matéria documental confiável. Não se trata, propriamente, de um documento. Onde e com quem se encontra esse registro? Datas em que foram ouvidos ou registrados? Local em que foram concedidos?

E quem afirma que ela contraiu sífilis? Foi ainda Clarice? Ou já foi uma conclusão do autor Moser? Isso também não fica claro. Onde termina o suposto depoimento e começa a interpretação? Se assim foi, valem para essa afirmação as mesmas indagações antes referentes ao registro documental. Se foi o autor do livro que emenda a sua própria voz à da depoente para diagnosticar a doença, mais um dado de afirmação forçada, para favorecer a sua frágil argumentação.

\section{E o autor continua:}

Se tivesse acesso mais rápido a um hospital, talvez houvesse alguma chance. Mas só vinte anos mais tarde a penicilina, o tratamento mais eficaz, iria se tornar de uso comum. A seu tempo, depois de uma década de horrível sofrimento, Mania, a garota elegante, inteligente e de espírito livre dos campos da Podólia, iria jazer num cemitério brasileiro. (p.48)

Na continuação, o "pressuposto" de que o estupro realmente é "fato consumado". De que a mãe contraiu sífilis a partir do estupro. E de que mais tarde "iria jazer num cemitério brasileiro" por causa dessa doença.

Constrói-se, assim, a narrativa "imaginária” do estupro, como se verdade fosse.
Nos parágrafos seguintes, Moser fala dos segredos de Clarice, das coisas não contadas. Que podem ter sido muitas, aliás! E afirma que “todos (grifo meu) os relatos dos pogroms registram a presença generalizada do estupro" (p.48). E conclui: "Na Ucrânia da época da guerra civil não foi diferente" (p.48, grifo meu). A partir dessa argumentação do autor, impossível ter havido violência sem algum estupro... Portanto... fica provada a sua tese. Está sacramentado o estupro. E, por consequência, a doença.

É assim que caminha a argumentação "cerrada" do autor... A partir daí, referese com tranquilidade à "mãe sifilítica" (p.48). E o que entra em questão é já a data em que "tal fato aconteceu": "é difícil saber exatamente quando Mania Lispector foi atacada" (p.48, grifo meu), ou quanto "foi estuprada" (p.49). Depois refere-se ao nascimento de Clarice, então chamada Chaya, em 20 de dezembro de 1920, já transformada em filha “de mãe sifilítica".

Apenas em nota de rodapé, agrupada, como as demais, no final do livro (distante do fluxo narrativo do corpo do texto), Moser inclui possíveis teses contrárias, e aí, acertadamente - é de inferir -, como teses "possíveis", ou seja, hipóteses: "Outras fontes atribuem a paralisia de Mania a um choque traumático (possivelmente um espancamento) ocasionado pela violência do pogrom ou por outra doença". E acrescenta importante afirmação: "Não se conhecem depoimentos das filhas de Mania, Tânia Kaufmann e Elisa Lispector, que confirmem a hipótese do estupro" (p.566, nota 7).

Além de discutir a "causa da sífilis" (p.50) e de remeter a datas prováveis em que esse estupro aconteceu (não em que "teria possivelmente acontecido", como 


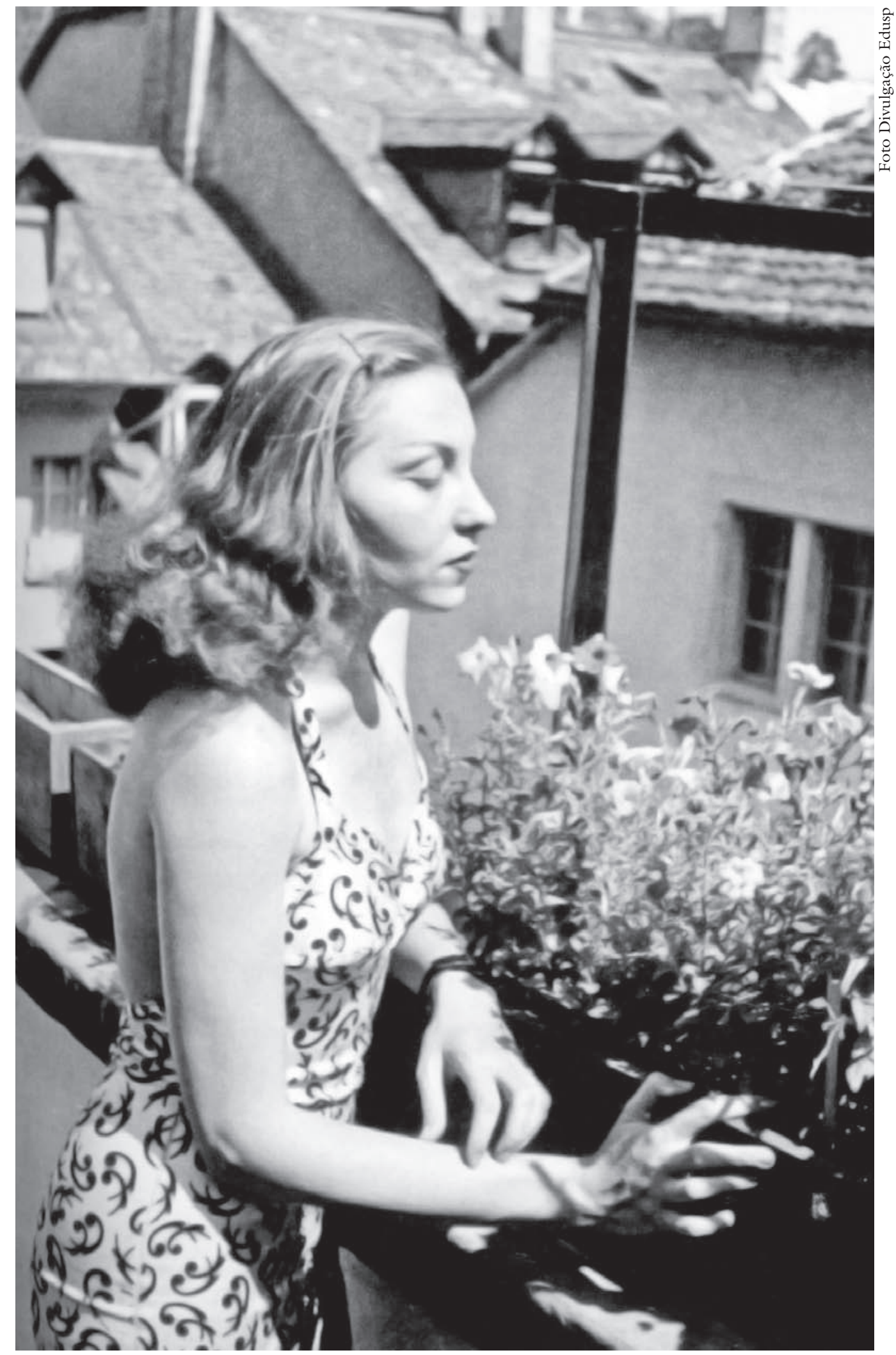

A escritora Clarice Lispector. 
seria recomendável), recorre ao romance autobiográfico de Elisa Lispector, No exílio, para comprovar sua "tese". Cita a cena do romance em que a narradora descreve um pogrom, mas em que não há nenhuma especificação de estupro. O autor preenche com sua interpretação o silêncio que existe na narrativa. Trata-se, pois, de uma interpretação, construída como uma hipótese, que ele, uma vez mais, transforma em certeza.

Esse fato do passado é peça fundamental, aliás, para argumentação subsequente do autor. Tenta-se, realçando esse fato do passado, reforçar assim o possível trauma que seria responsável por um tipo de escrita diretamente ligada às origens judaicas, ou seja, a concepção de Deus segundo a tradição cultural judaica: a busca do nome, mas enquanto "nome sagrado, sinônimo de Deus" (p.232).

Não há, pois, matéria documental que comprove que a mãe de Clarice foi estuprada. Nem que teria nessa ocasião contraído sífilis. Nem, ainda, que teria morrido por causa de sífilis.

Para finalizar, é de mencionar que na edição norte-americana da biografia de Moser, editada com o título de Why this world (Oxford University Press, 2009), outros detalhes de biografias anteriores são incorporados. Ali surge um mapa do Brasil e um mapa da Ucrânia, com localização das cidades pelas quais passou a família Lispector, proposta de ilustração que aparece na edição de Clarice fotobiografia, de Gotlib. (O mapa com indicação das cidades da Ucrânia e países adjacentes também surge na edição brasileira da biografia de autoria de Moser.)

Ainda na edição norte-americana do livro de Moser é registrada uma árvore genealógica da família Lispector, Krimgold e Rabin, tal como na última pá-

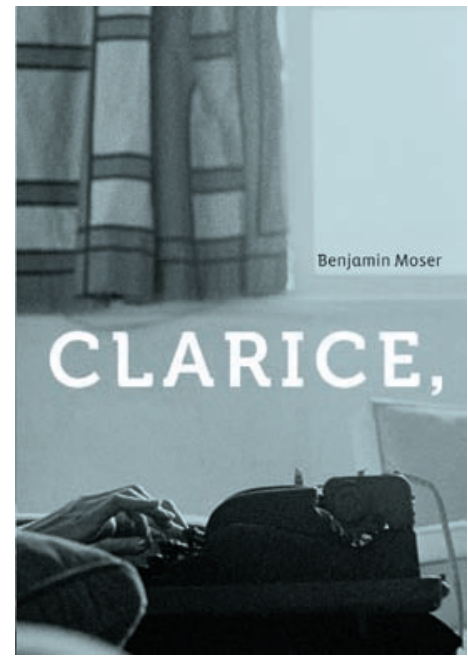

MOSER, Benjamin. Clarice,

Trad. José Geraldo Couto. São Paulo:

Cosac Naify, 2009.

gina da mencionada biografia de autoria de Teresa Cristina Montero Ferreira, de 1999.

Ali também é editada uma minifotobiografia com seleção de 35 imagens. Dessas, 32 aparecem no livro Clarice fotobiografia, de Nádia Gotlib (algumas delas, também na primeira e última edições de Clarice, uma vida que se conta). O autor menciona os créditos mencionados pela autora em seu livro Clarice fotobiografia, mas não menciona o livro Clarice fotobiografia como fonte dessa seleção. No entanto, tais imagens são também produto de pesquisa que tem autoria: foram consultados vários arquivos para reunir o vasto repertório, com dados informativos nas legendas.

O que acontece nesse caderno de imagens - seleção espelhada de um intenso trabalho de pesquisa com imagens, feita por Nádia Gotlib, que redundou na extensa fotobiografia - é o que acontece também em muitos momentos do texto 
de Moser, em que reconheço igualmente o espelhamento da biografia de Clarice de autoria de Nádia Gotlib, patente nas opções de estrutura do texto, no modo de conduzir e organizar a matéria, nos textos selecionados para integrar a exposição.

Do ponto de vista da crítica literária, no seu intuito de perseguir "os motivos judaicos nos escritos de Clarice Lispector", no livro de Moser, a literatura de Clarice fica relegada a um pano de fundo. Com o intuito de demonstrar essa sua proposta, instaura-se uma leitura dos textos de Clarice sem a consideração de que textos de memória são também construção do imaginário, e assim considerados, não se apresentam mais como provas de um território eminentemente factual.

O risco que corre é a tentação de encontrar na ficção cenas da vida da escritora, como na leitura que faz do conto "Uma galinha", em que a personagem, uma galinha, escapa de ser morta porque bota um ovo. E, assim, é salva, pelo milagre da criação. Segundo Moser,

[...] a referência ao "velho susto de sua espécie" sugere o ancestral medo judaico de perseguição, e a frase "resquícios da grande fuga", combinada com o espetáculo de uma fêmea impotente, grávida e incapaz de voo que corre para salvar a vida, remete à desesperada fuga da Europa empreendida por sua mãe. (p.297).

Por essas razões, convém revisitar o livro Clarice, uma vida que se conta, de Nádia Battella Gotlib, para reforçar os laços de aproximação com a literatura de Clarice, aí percebida a partir de recursos literários tão sutilmente utilizados pela escritora Clarice. Ainda mais agora que esse livro reaparece sob uma nova luz: a de seu correspondente em imagens, o notável
Clarice fotobiografia, da mesma autora. E convém recorrer ao livro de Benjamin Moser para buscar aí dados sobre a tradição histórica judaica que provocou a saga dos movimentos migratórios, incluindo os da família Lispector, dados que, no entanto, merecem toda a atenção, já que ao lado de um vasto repertório de informações de interesse encontram-se argumentos discutíveis, expostos num fluxo de linguagem sedutor e envolvente.

Benjamin Abdala Junior é professor de Estudos Comparados de Literaturas de Língua Portuguesa da Faculdade de Filosofia, Letras e Ciências Humanas da Universidade de São Paulo.

(1) - benjaminjr@terra.com.br 